ВІСНИК

ОДЕСЬКОГО НАЦІОНАЛЬНОГО

МОРСЬКОГО УНІВЕРСИТЕТУ
HERALD

OF THE ODESSA NATIONAL

MARITIME UNIVERSITY № 3 (60), 2019

УДК 536.24(075.8)

DOI 10.33082/2226-1893-2019-3-81-85

\title{
ПОВЫШЕНИЕ НАЧАЛЬНОЙ ТЕМПЕРАТУРЫ ПАРА ДЛЯ ИСКЛЮЧЕНИЯ ЕГО ПРОМЕЖУТОЧНОГО ПЕРЕГРЕВА
}

\author{
А.A. Вассерман \\ доктор технических наук, профессор кафедры \\ «Судовые энергетические установки и техническая эксплуатация» \\ Одесский национальный морской университет, Одесса, Украина
}

\begin{abstract}
Аннотация. Рассматривается возможность исключения промежуточного перегрева пара в цикле паротурбинной установки (ПТУ) путём повышения начальной температуры пара. Приведены результаты расчётов при начальном давлении пара 6, 8 и 10 МПа и давлении конденсачии 0,004 и 0,005 МПа. Анализ результатов показал, что возможно исключение промежуточного перегрева при указанных значениях начального давления и минимально допустимой степени сухости пара в конще расширения в турбине 0,86 при повышении начальной температуры пара до $800^{\circ} \mathrm{C}$.
\end{abstract}

Ключевые слова: паротурбинная установка, промежуточный перегрев пара, температура и давление пара, степень сухости пара.

УДК 536.24(075.8)

DOI 10.33082/2226-1893-2019-3-81-85

\section{ПІДВИЩЕННЯ ПОЧАТКОВОЇ ТЕМПЕРАТУРИ ПАРИ ДЛЯ ВИКЛЮЧЕННЯ ЇЇ ПРОМІЖНОГО ПЕРЕГРІВУ}

\section{О.А. Вассерман}

доктор технічних наук, професор кафедри

«Суднові енергетичні установки та технічна експлуатація»

Одеський національний морський університет, Одеса, Україна

Анотація. Розглядається можливість виключення проміжного перегріву пари в ииклі паротурбінної установки (ПТУ) шляхом підвищення початкової температури пари. Наведені результати розрахунків при початковому тиску пари 6, 8 і 10 МПа і тиску конденсації 0004 i 0,005 МПа. Аналіз результатів показав, що можливо виключення проміжного перегріву при вказаних значеннях початкового тиску $і$ мінімально допустимому ступені сухості пари наприкінці розширення в турбіні 0,86 при підвищенні початкової температури пари до $800^{\circ} \mathrm{C}$.

Ключові слова: паротурбінна установка, проміжний перегрів пари, температура и тиск пари, степінь сухості пари.

(C) Вассерман А.A., 2019 
UDC 536.24(075.8)

DOI 10.33082/2226-1893-2019-3-81-85

\title{
RISE INITIAL TEMPERATURE OF VAPOR FOR EXCLUSION ITS INTERMEDIATE OVERHEATING
}

\author{
A.A. Vasserman \\ Doctor of technical sciences, Profesor of department \\ «Ships energetic plants and technical operation» \\ Odessa National Maritime University, Odessa, Ukraine
}

\begin{abstract}
The possibility of exclusion intermediate overheating of vapor at steam-turbine plants (STP) cycle by rise initial temperature of vapor is considered. Results of calculations at initial pressure of vapor 6, 8 and 10 MPa and condensation pressure 0,004 and 0,005 MPa are presented. The analysis of results showed, that it is possible exclusion intermediate overheating at indicating values initial pressure and minimum admissible degree of vapor dryness at end of expansion in turbine 0,86 at rise initial temperature of vapor to $800^{\circ} \mathrm{C}$.
\end{abstract}

Keywords: steam-turbine plant, intermediate overheating of vapor, temperature and pressure of vapor, degree of vapor dryness.

Введение. Промежуточный перегрев пара применяется в паротурбинных установках для обеспечения приемлемого значения степени сухости пара в конце его расширения в турбине [1-4]. Однако применение промежуточного перегрева пара несколько усложняет конструкцию котельного агрегата. В настоящей работе рассматривается возможность исключения промежуточного перегрева при сохранении допустимого значения степени сухости пара в конце расширения.

Целью статьи является определение при заданных значениях начального давления пара и давления конденсации значения начальной температуры пара, при которой возможен отказ от применения промежуточного перегрева.

Изложение основного материала. На рис. 1 представлены в координатах $T, s$ цикл ПТУ с промежуточным перегревом пара и цикл без промперегрева с более высокой начальной температурой пара. Из рисунка видно, что для исключения промежуточного перегрева при сохранении той же степени сухости пара в конце расширения в турбине необходимо повысить начальную температуру пара. Повышение начальной температуры пара, естественно, повысит термический КПД цикла ПТУ.

В настоящее время начальная температура пара в мощных паротурбинных установках равна $500-550{ }^{\circ} \mathrm{C}$, в некоторых случаях достигает $600{ }^{\circ} \mathrm{C}$. При этих значениях начальной температуры и высоком начальном 
давлении пара необходимо применять промежуточный перегрев. Ограничение максимальной температуры пара обусловлено снижением прочности трубок пароперегревателя при высоких температурах. Применение для этих трубок специальных марок стали с повышенной жаропрочностью может позволить исключить промежуточный перегрев путём повышения начальной температуры пара. Поэтому в данной работе при нескольких значениях начального давления пара определены значения его начальной температуры, при которых возможно исключение промежуточного перегрева.

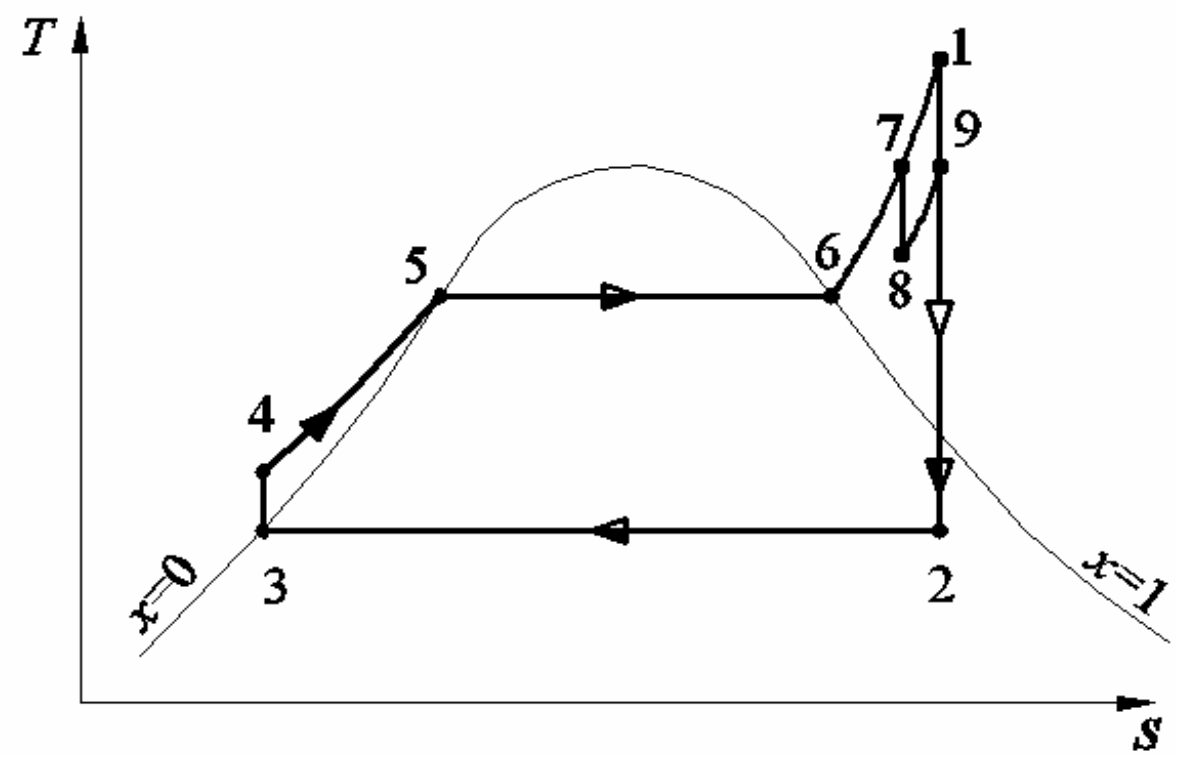

Рис. 1. Циклы ПТУ с промежуточным перегревом пара 7-8-9-2-3-4-5-6-7 и без промперегрева 1-2-3-4-5-6-1

Для исследования были приняты значения начального давления 6 , 8 и 10 МПа, давления конденсации 0,004 и 0,005 МПа и допустимого значения степени сухости пара в конце расширения 0,86 и 0,90 . При расчётах использованы данные о термодинамических свойствах воды и водяного пара из таблиц М.П. Вукаловича и соавторов [5]. Результаты расчётов представлены в таблице.

Анализируя данные таблицы, можно установить следующее:

- если изготовить трубки пароперегревателя из стали, способной выдержать температуру пара до $800{ }^{\circ} \mathrm{C}$, и принять минимально допустимое значение степени сухости пара в конце расширения 0,86, то при начальном давлении пара до 10 МПа можно исключить промежуточный перегрев за счёт повышения начальной температуры пара; 
- при более высоком значении степени сухости пара в конце расширения 0,90 и начальном давлении пара 6-10 МПа значение начальной температуры пара, необходимое для исключения промежуточного перегрева, как правило, превышает $800{ }^{\circ} \mathrm{C}$.

Таблица

Значения начальной температуры пара, позволяющие исключить его промежуточный перегрев

\begin{tabular}{|c|c|c|c|}
\hline $\begin{array}{c}\text { Начальное } \\
\text { давление, МПа }\end{array}$ & $\begin{array}{c}\text { Давление } \\
\text { конденсации, МПа }\end{array}$ & $\begin{array}{c}\text { Степень } \\
\text { сухости } x_{2}\end{array}$ & $\begin{array}{c}\text { Начальная } \\
\text { температура } t_{1}{ }^{\circ} \mathrm{C}\end{array}$ \\
\hline 6 & 0,004 & 0,8605 & 670 \\
\hline 6 & 0,005 & 0,8603 & 645 \\
\hline 8 & 0,004 & 0,8605 & 728 \\
\hline 8 & 0,005 & 0,8602 & 702 \\
\hline 10 & 0,004 & 0,8605 & 775 \\
\hline 10 & 0,005 & 0,8602 & 748 \\
\hline 6 & 0,004 & 0,9001 & 805 \\
\hline 6 & 0,005 & 0,8999 & 775 \\
\hline 8 & 0,004 & 0,8998 & 867 \\
\hline 8 & 0,005 & 0,8999 & 837 \\
\hline 10 & 0,004 & 0,9004 & 920 \\
\hline 10 & 0,005 & 0,9002 & 888 \\
\hline
\end{tabular}

Материал узлов турбины способен выдержать повышение начальной температуры пара до $800{ }^{\circ} \mathrm{C}$. Трубу, подводящую к турбине пар, потребуется изготовить из жаростойкой стали.

Выводы. Расчёты цикла ПТУ позволили определить значения начальной температуры пара, при которых можно отказаться от применения его промежуточного перегрева. Упрощение конструкции котельного агрегата и экономия топлива благодаря росту термического КПД цикла ПТУ окупят расходы, связанные с изготовлением трубок пароперегревателя из жаростойкой стали. Эту возможность следует учитывать при проектировании паротурбинных установок. 
ВІСНИК

ОДЕСЬКОГО НАЦІОНАЛЬНОГО

МОРСЬКОГО УНІВЕРСИТЕТУ

№ 3 (60), 2019
HERALD

OF THE ODESSA NATIONAL

MARITIME UNIVERSITY

№ $3(60), 2019$

\section{СПИСОК ЛИТЕРАТУРЫ}

1. Техническая термодинамика / В.А. Кириллин, В.В. Сычев, А.Е. Шейндлин. М.: Издательский дом МЭИ, 2008. 496 c.

2. Техническая термодинамика / М.П. Вукалович, И.И. Новиков. М.: Энергия, 1968. 496 c.

3. Лекции по технической термодинамике / Я.3. Казавчинский. М.: Транспорт, 1970. 275 c.

4. Термодинамічні процеси та иикли в реальному газі / О.А. Вассерман, О.Г. Слинько. Одеса: Фенікс, 2015. 194 с.

5. Таблицы теплофизических свойств воды и водяного пара / М.П. Вукалович, С.Л. Ривкин, А.А. Александров. М.: Изд-во Стандартов. 1969. 408 c.

\section{REFERENCES}

1. Kirillin V.A., Sychev V.V., Sheydlin A.E.(2008) Texnicheskaya termodinamika [Technical thermodynamics] Moscov: Izdatelskii dom MEI.(in Russian)

2. Vukalovich M.P., Novikov I.I. (1968) Texnicheskaya termodinamika [Technical thermodynamics] Moscov:E'nerhiya.(in Russian)

3. Kazavchinskiy Ya.Z. (1970) Lektsii po texnicheskoi termodinamike [Lectures on technical thermodynamics] ] Moscov:Transport.(in Russian)

4. Vasserman O.A., Slyn'ko O.G.(2015) Termodinamichni protsessy ta tsykly v real'nomu gazi [Technological processes and cycles in real gas]Odesa:Feniks. (in Ukrainian)

5. Vukalovich M.P., Rivkin S.L., Aleksandrov A.A. (1969) Tablitsy' teplofizicheskix svoystv vody' $i$ vodyanogo para [Tables of technological properties of water and water vapor] Moscov:Izdatelstvo Standartov. (in Russian)

Стаття надійшла до редакиії 05.12.2019 